RICARDO MÁRIO GONÇALVES

As flores do dharma

desabrocham

sob o Cruzeir do Sul:

RICARDO MÁRIO

GONCALVES

é professor de História da Universidade de São Paulo.

\title{
aspectos dos
}

vários "budismos"

no Brasil 
Discorrer sobre o budismo no Brasil significa, para mim, trabalhar com uma história da qual sou ao mesmo tempo um dos estudiosos e um dos personagens. Com efeito, tendo começado a me interessar pela tradição budista ainda na adolescência, em fins dos anos 50, muito antes dessa doutrina começar a chamar a atenção do público brasileiro, sou hoje reconhecido nos meios budistas nacionais como um dos pioneiros do processo de introdução da mesma em nosso país. Portanto, este é um relato feito por um observador participante que, a exemplo de outro artigo publicado em 2002 ( I ), possui um caráter predominantemente autobiográfico e tem por principal objetivo resgatar a memória de certos fatos que, sem esta iniciativa, possivelmente ficariam esquecidos.

Principio apresentando uma breve noção do que seja o budismo. A palavra budismo vem do sânscrito Buddha (desperto). Esse adjetivo geralmente é empregado para designar o fundador histórico do budismo, o príncipe Siddhartha Gautama, que teria vivido 
no nordeste da Índia há mais ou menos 2.500 anos. Segundo a perspectiva gnóstica própria do budismo, o homem comum viveria mergulhado num estado comparável ao sono ou à embriaguez, ignorante de sua verdadeira natureza, bem como da do universo em que se encontra situado. O Buda histórico Gautama, também conhecido como Sakyamuni (o sábio silencioso da tribo sakya), teria sido o primeiro ser humano a despertar para esse conhecimento, alcançando através do mesmo a libertação de todos os sofrimentos e angústias inerentes à condição humana, e passando a ensiná-lo aos demais. Podemos sintetizar o budismo em três princípios fundamentais: impermanência, insubstancialidade e nirvana.

Princípio de impermanência: os seres humanos e o mundo que habitam são fruto de um contínuo processo de transformação. Nadaé estável. Todas as coisas se encontram num constante vir-a-ser. Tudo é impermanente e efêmero. Não há lugar no mundo para um Deus imutável e eterno, nem para almas imortais. O ser humano não pode mudar a natureza e a sequiência dos fenômenos em função de seus interesses e desejos e, por isso, sente e experimenta a impermanência das coisas como algo indesejável, como angústia e sofrimento.

Princípio de insubstancialidade ou não$e u$ : neste contínuo vir-a-ser nada existe de substancial e definitivo. Nenhum fenômeno existe independentemente do contexto em que se situa, e seu destino é transformar-se quando o contexto se modifica. As coisas não se definem pelo que elas seriam em si, mas sim pela rede de condicionamentos e relacionamentos que as ligam ao contexto. O ser humano, analisando-se, nada encontra em si mesmo e a seu redor, nada a que possa se apegar como sendo seu "eu", sua personalidade substancial. Segundo o Buda, o homem nada mais é do que um conjunto de agregados psicofísicos, todos impermanentes e insubstanciais. Entretanto, a ignorância, o egoísmo e as paixões humanas levam-no a alimentar a ilusão de que as coisas não se transformam e a tomá-las por possuidoras de uma essência perene.

Nasce daío apego às coisas experimentadas através dos sentidos, o anseio por uma vida eterna ou, então, o seu oposto, o desejo mórbido e niilista da aniquilação total. $\mathrm{O}$ ser humano sofre porque projeta desejos de estabilidade e permanência em coisas efêmeras e relativas.

Princípio do nirvana ou do incondicionado: entretanto, por trás do relativo e impermanente haveria um real incondicionado e permanente. O ser humano poderá atingi-lo ou experimentá-lo aprendendo a se desapegar do impermamente e do relativo, aceitando-os como tais, assumindo a transformação de si mesmo e de todas as coisas, com todas as suas conseqüências. Quando isso ocorre, o homem experimenta o nirvana, isto é, o incondicionado, que o Buda jamais define, limitando-se a dizer que ele é caracterizado pela aniquilação do sofrimento e de suas causas: a ignorância, a cólera e as paixões descontroladas.

Diz a tradição que o Buda deixou 84.000 dharmas ou doutrinas. Isso quer dizer que o Buda dava mais importância a conduzir as pessoas ao despertar do que a enunciar dogmas. As doutrinas não passam de "hábeis meios salvíficos" (sânscrito upaya) para encaminhar as pessoas ao despertar. Por isso mesmo variam elas bastante não só em função do caráter das pessoas, mas também por causa das diferenças culturais e sociais dos meios em que o budismo foi implantado. Além disso, ele passou por várias importantes mudanças de paradigma durante sua longa história (2). Disso tudo resulta tamanha variedade de escolas, estilos e formas de culto e vivência que opto, com Bernard Faure (1998), por empregar a palavra no plural: "budismos".

Apresento um panorama simplificado do universo dos "budismos", enfatizando as formas hoje presentes no Brasil. Temos em primeiro lugar o Theravada ou Escola dos Anciães, às vezes impropriamente rotulada de Hinayana ou Pequeno Veículo. Dominante nos países do Sudeste Asiático (Tailândia, Sri Lanka, Miyanmar), privilegia a vida monástica, a estrita observância de regras e preceitos e a prática da meditação. É representado no Brasil por três grupos principais: 1) Sociedade Budista do Brasil, de mudança paradigmática a história das religiões e à do budismo, em particular, ao teólogo católico Hans Küng. 
fundada no Rio de Janeiro em 1955 e reativada em 1967 pelo budista brasileiro dr. Murillo Nunes de Azevedo com a minha colaboração; segue a orientação dos monges Theravadin do Sri Lanka; 2) Centro de Estudos Budistas Nalanda, sediado em Belo Horizonte, foi fundado em 1989 pelo prof. Ricardo Sasaki e segue a tradição thai-birmanesa; 3) Casa do Dharma, instituição sediada em São Paulo e presidida pelo antropólogo dr. Arthur Shaker.

Em segundo lugar, temos o Mahayana ou Grande Veículo, predominante na China, no Japão, na Coréia e no Vietnã. Corrente originária do norte da Índia, abriu-se a influências persas e helenísticas, propondo como modelo de conduta a figura do Bodhisattva, adepto que coloca em primeiro lugar sua contribuição para a salvação de todos os seres, adiando indefinidamente seu despertar pessoal. Sem abandonar a tradição monástica, abre amplo espaço para formas centradas no laicato. Desenvolveu

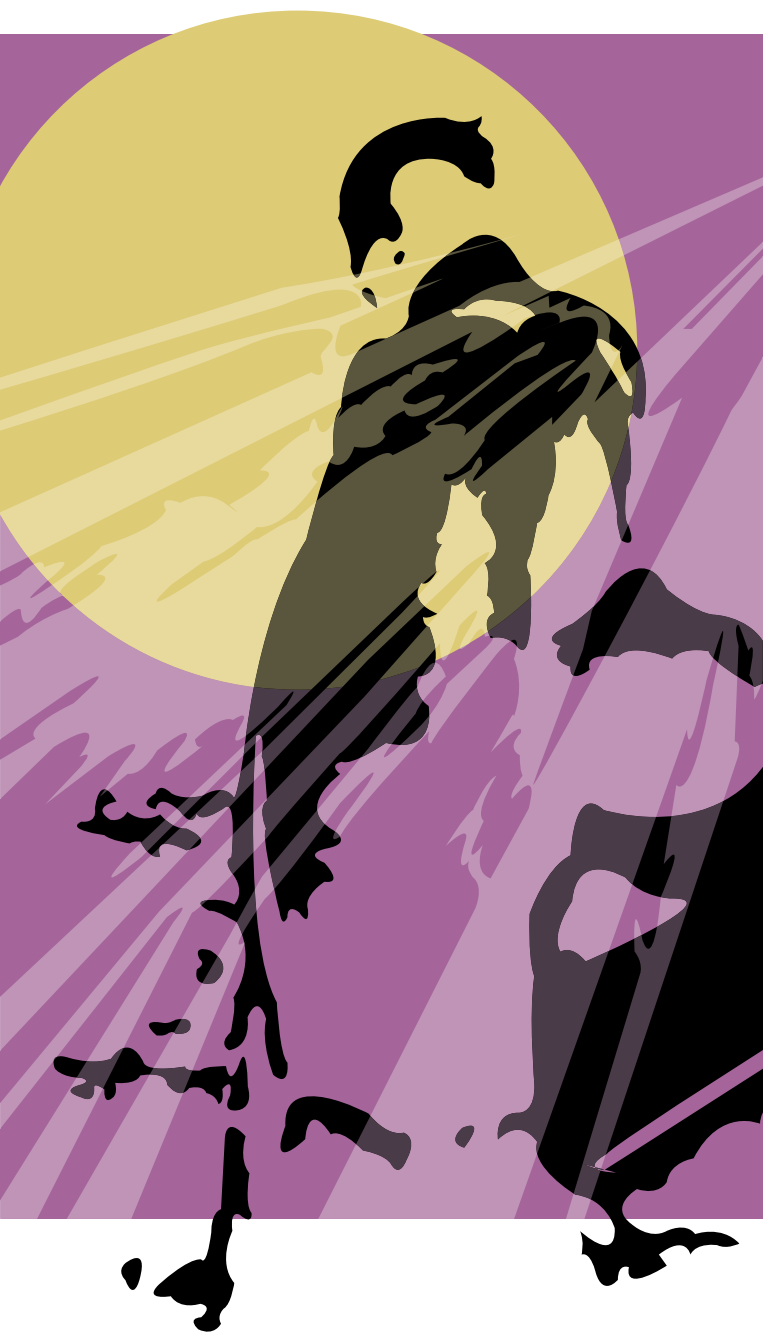

importantes correntes filosóficas, como a Escola do Vazio de Nagarjuna (entre 150 e 250 de nossa era) e a Escola da Consciência de Vasubandhu (320-400). É representado no Brasil por escolas japonesas, chinesas e coreanas. As escolas japonesas são as mais antigas em nosso país. Ainda que os imigrantes japoneses tenham chegado ao Brasil a partir de 1908, desenvolveram poucas atividades religiosas aqui, pois sua intenção era trabalhar no Brasil alguns anos, amealhar um patrimônio e regressar ao Japão. Entretanto, a derrota do Japão tornou esse regresso impossível, e os nipônicos, resolvendo fazer do Brasil sua segunda pátria, trouxeram para cá suas instituições religiosas. As primeiras missões budistas oficiais remontam a 1952. As principais escolas japonesas do budismo Mahayana presentes em nosso país são o zen (ramo soto), uma escola contemplativa, o jodo e o shin (ramos honpa e otani), escolas devocionais pertencentes a uma linhagem conhecida como Terra Pura, centralizada na devoção ao Buda Amitabha (Amida em japonês) cujo nome é recitado pelos devotos como principal via para a salvação - prática doNembutsu -, e a Escola Nichiren, de forte teor nacionalista.

As escolas budistas chinesas, coreanas e vietnamitas chegaram ao Brasil em época mais recente e se caracterizam pelo ecletismo que combina a prática da meditação zen ( $C h$ 'an em chinês) com a prática da recitação do Nome de Amitabha. A ordem budista chinesa que mais se destaca em nosso país é a Fo Guang Shan, com sede em Taiwan, liderada pelo mestre Hsing Yün, responsável pela construção em Cotia, na Grande São Paulo, do Templo Zu Lai, o maior templo budista da América Latina, inaugurado em 2002. Liderada por uma missionária, a monja Sinceridade, a missão brasileira da ordem Fo Guang Shan desenvolve em Cotia intensa atividade assistencial e educativa junto à população carente, mantendo uma escola primária e secundária - Colégio Siddhartha - e a primeira universidade budista da América do Sul, destinada à formação de monges e instrutores budistas leigos. O Zu Lai conta 
ainda com um Centro de Meditação no bairro da Liberdade, São Paulo, e com sucursais no Rio de Janeiro e em Olinda.

O budismo coreano é representado no Brasil pelo templo Jingak-sa, em São Paulo, e o vietnamita pela escola Thien-Lam-te, a que pertence o mestre Thich Nhat Hanh, militante pacifista mundialmente conhecido que vive hoje em Plum Village, um centro para a prática espiritual no sudoeste da França. Essa escola está presente no Brasil desde o final dos anos 90 através de vários grupos de discípulos leigos sediados no Rio de Janeiro, entre os quais se destaca o centro Lótus, coordenado por Hildeth Farias, e o Zhong Dao, liderado por Cláudio Miklos.

Em terceiro lugar, temos o Vajrayana (Veículo do Raio ou do Diamante) ou budismo tântrico, um desenvolvimento tardio do Mahayana carregado de misticismo, magia e simbolismo sexual que floresce principalmente no Tibete, na Mongólia e entre os buriatos da Rússia, mas que está presente também na China e no Japão. No Brasil está presente através da escola Shingon, trazida pelos imigrantes brasileiros e por vários movimentos de origem tibetana (3). Até meados do século XX o Tibete era um país praticamente isolado do resto do mundo. A traumática invasão do mesmo pela China comunista em 1950, seguida pela fuga do Dalai Lama, dirigente temporal e espiritual tibetano, para a Índia em 1958, desencadeia uma verdadeira diáspora tibetana que tem por consequiência a difusão do Vajrayana no Ocidente por mestres obrigados a se exilarem. Muito antes de os movimentos budistas tibetanos começarem a se instalar no Brasil a partir dos fins dos anos 80, a USP foi pioneira da apresentação da arte religiosa tibetana entre nós. Em 1969, por minha intermediação, a Fundação Apis Tibetana realizou no então Museu de Arte e Arqueologia (hoje Museu de Arqueologia e Etnologia) da USP uma exposição de esculturas e pinturas tibetanas pertencentes aos colecionadores Eddy Novarro, Nana de Craiova e Murillo Nunes de Azevedo (Arte Tibetana, 1968). Hoje temos no Brasil várias organizações a representar várias escolas e tendências do budismo ti- betano, algumas lideradas por personagens dotados de projeção internacional. Assim, em São Paulo temos o Centro de Dharma De Choe Tsog cujo dirigente, Daniel Calmanovitz, é pai do jovem Michel Lenz César Calmanovitz, mais conhecido como Lama Michel. Reconhecido por seu mestre Lama Gangchen como um tulku ou manifestação em forma humana de um antigo mestre espiritual, Lama Michel divide seu tempo entre o Brasil, Milão, onde vive e atua o Lama Gangchen, e o mosteiro de Sera Me na Índia do Sul, onde está fazendo seus estudos. Temos também Segyu Rimpoche (Antônio), um brasileiro que começou sua busca espiritual no universo dos cultos afro-brasileiros (umbanda) e, depois de ser oficialmente reconhecido como tulku, tornou-se abade de um mosteiro tibetano no Nepal, sendo também diretor da Healing Buddha Foundation Segyu Gaden Dhargye Ling, na Califórnia. Há que destacar também o mestre Chagdud Tulku que veio

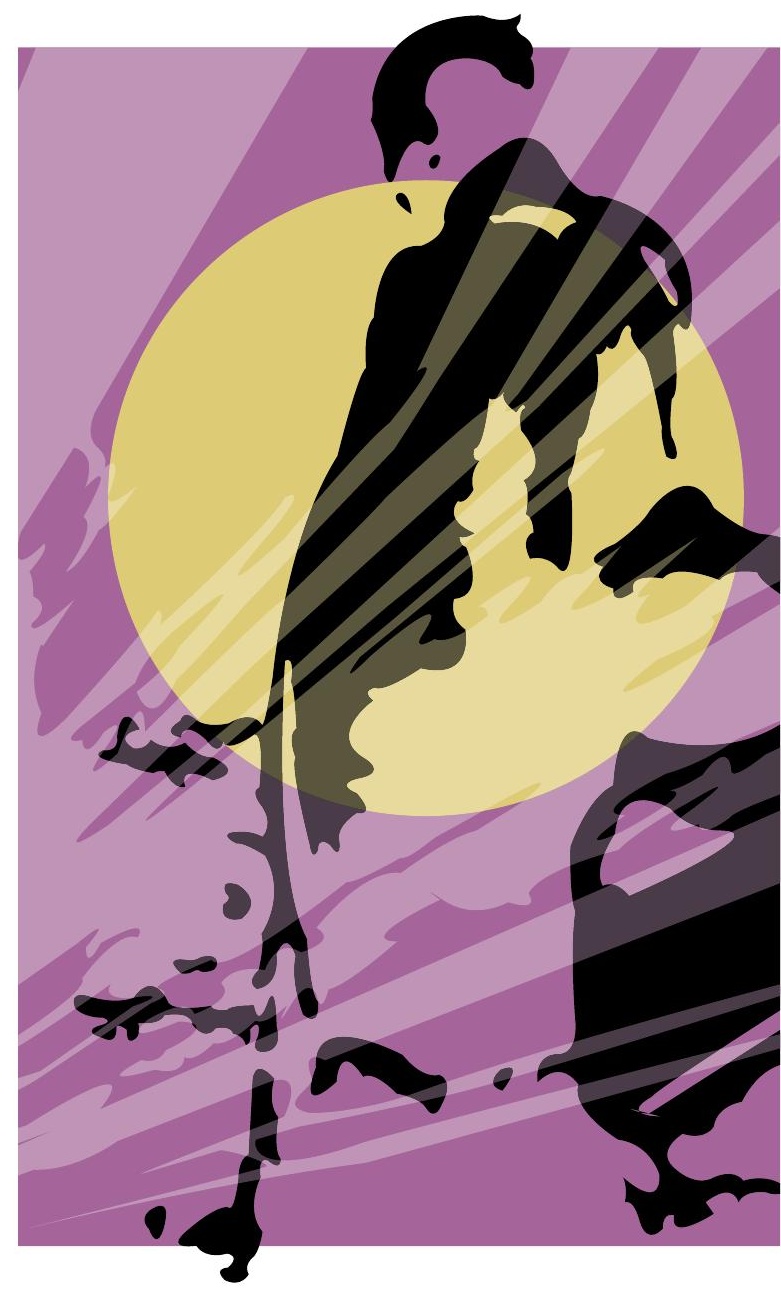

Paramaiores detalhes históricos e doutrinários do budismo consultar: Gonçalves, 1992. 
dos Estados Unidos para o Brasil em 1996. Fundou um templo tibetanoem Três Coroas, Rio Grande do Sul, onde faleceu em 2002, deixando como legado o Chagdud Gonpa Brasil, organização que conta com sucursais em várias metrópoles brasileiras. Formou vários discípulos, entre os quais destaco o Lama Padma Samten (Alfredo Aveline), que foi professor de física na Universidade Federal do Rio Grande do Sul por 25 anos (4). A essas correntes budistas tradicionais há que acrescentar neobudismos de vários matizes. Temos, em primeiro lugar, o budismo modernista criado pelos ocidentais para seu próprio uso, que privilegia os aspectos filosóficos e psicológicos da doutrina, deixando de lado a dimensão religiosa da mesma. Deixou várias marcas na literatura brasileira, dentre as quais destaco o soneto "Budismo Moderno" do poeta paraibano Augusto dos Anjos (1884-1914), composto em 1909 .

“Tome, Dr., esta tesoura, e... corte

Minha singularíssima pessoa.

Que importa a mim que a bicharia roa

Todo o meu coração depois da morte?!

Ah! Um urubu pousou na minha sorte! Também, das diatomáceas da lagoa A criptógama cápsula se esbroa Ao contato de bronca destra forte!

Dissolva-se, portanto, minha vida Igualmente a uma célula caída $\mathrm{Na}$ aberração de um óvulo infecundo;

Mas o agregado abstrato das saudades Fique batendo nas perpétuas grades Do último verso que eu fizer no mundo!" (in Magalhães Junior, 1977, pp. 199-200).

Há que lembrar também que campeiam no Ocidente versões do budismo deformadas por influências teosóficas e ocultistas e, mais recentemente, pelo pensamento new age. Temos ainda as pseudomorfoses japonesas do budismo, movimentos de massa de caráter laico inspirados nas doutrinas de Nichiren (1222-82) como a Reiyukai, a Risshokoseikai e a Soka Gakai, esta última com grande penetração entre os brasileiros. Ainda que consideradas por alguns pesquisadores (cf. Usarski, 2002) como escolas budistas, não são reconhecidas como tais pelas correntes budistas tradicionais nipônicas, sendo classificadas pelos especialistas japoneses como Shinkô Shûkyô (novas religiões). Não levo em conta essas organizações neste trabalho e adoto idêntica postura em relação a movimentos mais recentes plenos de influências neotântricas, teosófico-ocultistas e new age, classificados pelos estudiosos japoneses como Shin-Shin Shûkyô (novíssimas religiões), como o Agonshû, o Kôfuku no Kagaku (ciência da felicidade) (ambas presentes no Brasil) e o controvertido OM - A Verdade Suprema, hoje rebatizado como Aleph, responsabilizado pelos ataques terroristas com gás sarin ao metrô de Tóquio em 1994. Uma última pseudomorfose budista japonesa é a Shinrankai, organização laica inspirada no budismo shin, que conta com uma sucursal em São Paulo. Lembro que as organizações budistas de origem japonesa, chinesa e coreana no Brasil formam o que alguns estudiosos denominam "budismo de imigração", pois foram criadas pelos imigrantes para suprir suas aspirações espirituais. Já os movimentos Theravadin, tibetanos e vietnamitas foram criados por brasileiros, sem o respaldo de comunidades étnicas.

Quando me aproximei do budismo, nos fins dos anos 50, o único portal disponível para o ingresso no mesmo era constituído pelas missões japonesas com sede em São Paulo. Portal difícil de ser transposto, pois, além da barreira da língua, outros fatores dificultavam a comunicação. As missões japonesas se destinavam prioritariamente a celebrar funerais e cultos em memória dos ancestrais para os imigrantes, a exemplo do que fazem os templos no Japão. Por outro lado, as escolas budistas nipônicas privilegiam as doutrinas dos patriarcas japoneses, totalmente desconhecidos dos brasileiros, que esperavam encontrar nas missões um budismo centrado nos ensinamentos do Buda Sakyamuni. Além disso, muitos dos brasileiros que se aproximavam do budismo
4 A implantação do budismo tibetano no Brasil foi minuciosamente analisada, na ótica antropológica, por Ana Crisina lopes Nina, em sua tese de doutoramento Ventos da Impermanência - Um Estudo sobre a Re-signiticação do Budismo Tibetano no Contexto da Diáspora, ainda inédita. 


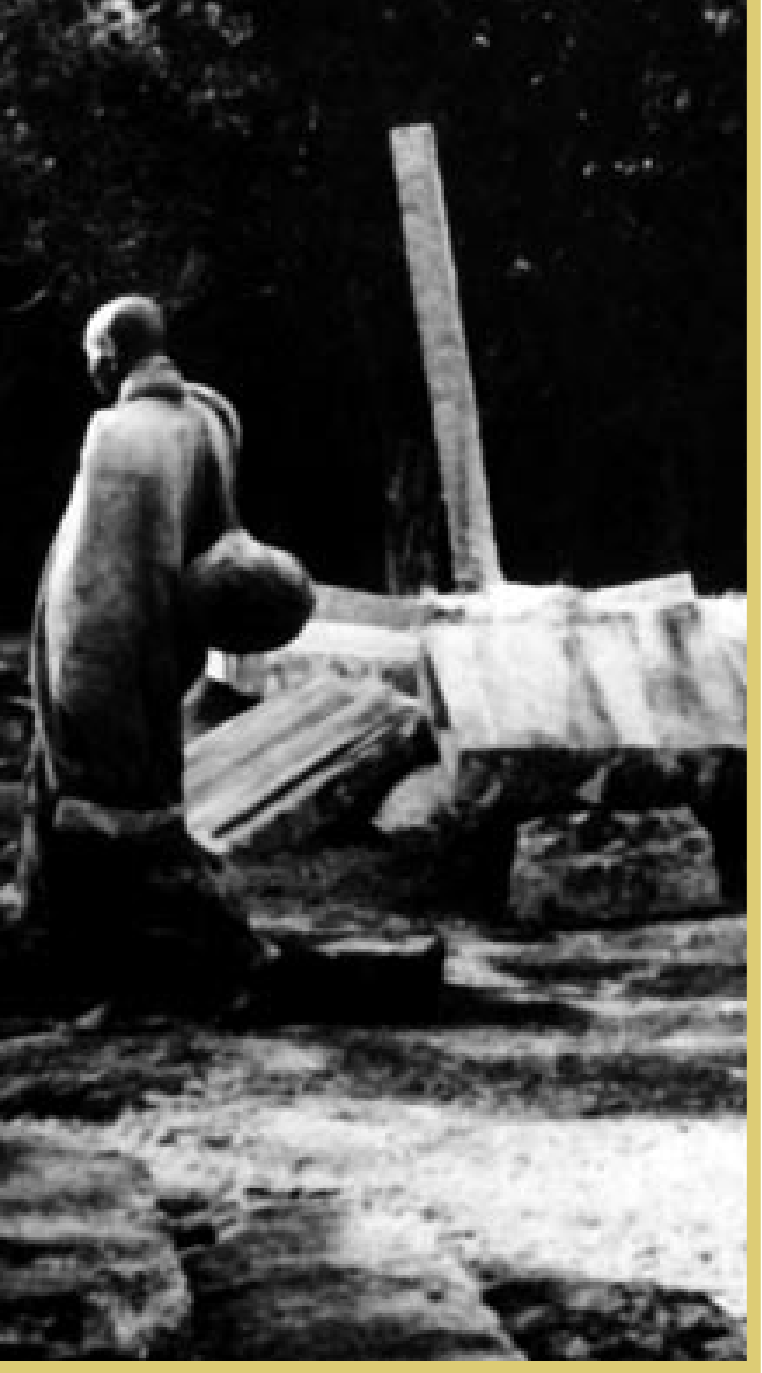

em Ibiraçu, Espírito Santo, o templo zen Pico dos Raios em Ouro Preto e o centro zen do Recife - Seirenji. Outro importante divulgador tem sido o mestre Moriyama que, depois de dirigir o Busshinji por dois anos, afastou-se do mesmo para atuar de forma independente no sul do país. Em 1995 regressou ao Brasil a monja brasileira Coen Murayama depois de vários anos de treinamento em Los Angeles e no Japão. Ela dirigiu o Busshinji até 2000, quando chegou do Japão um novo superior, o mestre Miyoshi. Ela foi obrigada a deixar o Busshinji e a fundar um grupo independente, o Tenzui Zen Dojo. Atualmente o novo superior do Busshinji, o mestre Saikawa, está trabalhando pela reconciliação entre os vários grupos soto zen existentes no país. Não posso deixar de citar outros importantes difusores do soto zen no Brasil, como Petrúcio Chalegre, de PortoAlegre, Getúlio Taigen, do Rio de Janeiro e Rui Ikko, de Campina Grande, Paraíba. Quero lembrar aqui que o sistema zen, que valoriza muito a relação entre mestre e discípulos, tende, independentemente da existência ou não de conflitos, a fragmentar o movimento em grupos que atuam independentemente uns dos outros. Outras escolas, comoo budismo shin, não admitem a relação entre mestre e discípulos e são muito mais centralizadas. No início dos anos 70 me afastei do zen e durante uma década me dediquei à escola Shingon de budismo Vajrayana. Em 1980 fui convidado para colaborar como Instituto Budistade Estudos Missionários criado pela missão sul-americana da ordem Otani de budismo shin. Isso me fez voltar ao shin, a primeira escola budista que eu conhecera ainda na adolescência. No instituto oriento a Oficina de Traduções Kumarajiva, um grupo de trabalho que está desenvolvendo métodos criteriosos de tradução dos textos sagrados da escola shin a partir das fontes originais.

Hoje em dia a Internet exerce importante papel na divulgação do budismo em nosso país. Destaco aqui o portal budista Dharmanet (www.dharmanet.com.br) que permite acessar sites budistas nacionais e internacionais, baixar traduções de textos sagrados de várias escolas, comprar livros budistas de uma livraria virtual, acompanhar um noticiário budista constantemente atualizado, etc. Também é possível participar de grupos de discussão sobre budismo em geral, zen, shin, Theravada e Vajrayana.

Quanto à situação do budismo no Brasil hoje em dia, vemos que a grande imprensa geralmente adota um tom triunfalista e sensacionalista, falando de um grande crescimento do número de budistas e da adesão ao dharma por parte de celebridades dos meios artísticos e jornalísticos. $\mathrm{Na}$ realidade, muitas dessas celebridades pertencem a pseudomorfoses neobudistas não reconhecidas pelas ordens tradicionais. Um recente estudo (Usarski, 2004) mostra, através das estatísticas do IBGE, que o número de budistas no Brasil tende a decrescer. O censo de 1991 registrou a existência de 236.408 budistas no país e o de 2000 mostrou que esse número baixou para 214.873. Esses números demandam algumas explicações e reflexões. 
Em primeiro lugar, considero esses números exagerados, já que incluem os devotos dos grupos neobudistas não reconhecidos pelo budismo tradicional. Em segundo lugar, essa diminuição se explica facilmente pelo fato de a grande maioria dos budistas no Brasil ser constituída de imigrantes japoneses e atualmente o Brasil não ser mais um país de imigração. Pelo contrário, hoje são os brasileiros descendentes de japoneses que se aventuram na terra de seus ancestrais em busca de melhores condições de vida (fenômeno dekassegui). Os velhos imigrantes vão morrendo e grande parte de seus descendentes não mais se define como budista, convertendose ao cristianismo ou aderindo às novas religiões japonesas. Entretanto, mesmo esses elementos recorrem esporadicamente aos templos para a celebração de ritos em memória dos ancestrais, em conformidade com a tradição nipônica.

Recente reportagem em revista semanal de grande circulação (5) enfatizou dramaticamente o caso do budismo shin, mostrando a diminuição do número de adeptos e o fechamento de templos por falta de fiéis e de missionários. As lideranças budistas estão cientes desses fatos e medidas estão sendo tomadas para que o chamado "budismo de imigração" se converta em budismo brasileiro. Em um $e$-mail recebido em 2/8/05 o professor de budismo Maurício Ghigonetto, filiado à ordem Honpa, me faz um esperançoso relato sobre um congresso de jovens budistas realizado recentemente em Araçatuba, que reuniu cerca de 200 participantes. Em terceiro lugar, devo dizer que os dados estatísticos não refletem necessariamente o real impacto do budismo sobre a sociedade brasileira. A maior parte das organizações budistas abre suas portas para os interessados em ouvir palestras, frequientar cursos ou participar de retiros de meditação sem exigir adesão formal dos mesmos ao budismo. Muitas pessoas têm tido suas vidas influenciadas ou transformadas pelo budismo sem necessariamente terem sentido necessidade de se converter ao mesmo. Muitos cristãos, por exemplo, têm participado de grupos de meditação budista

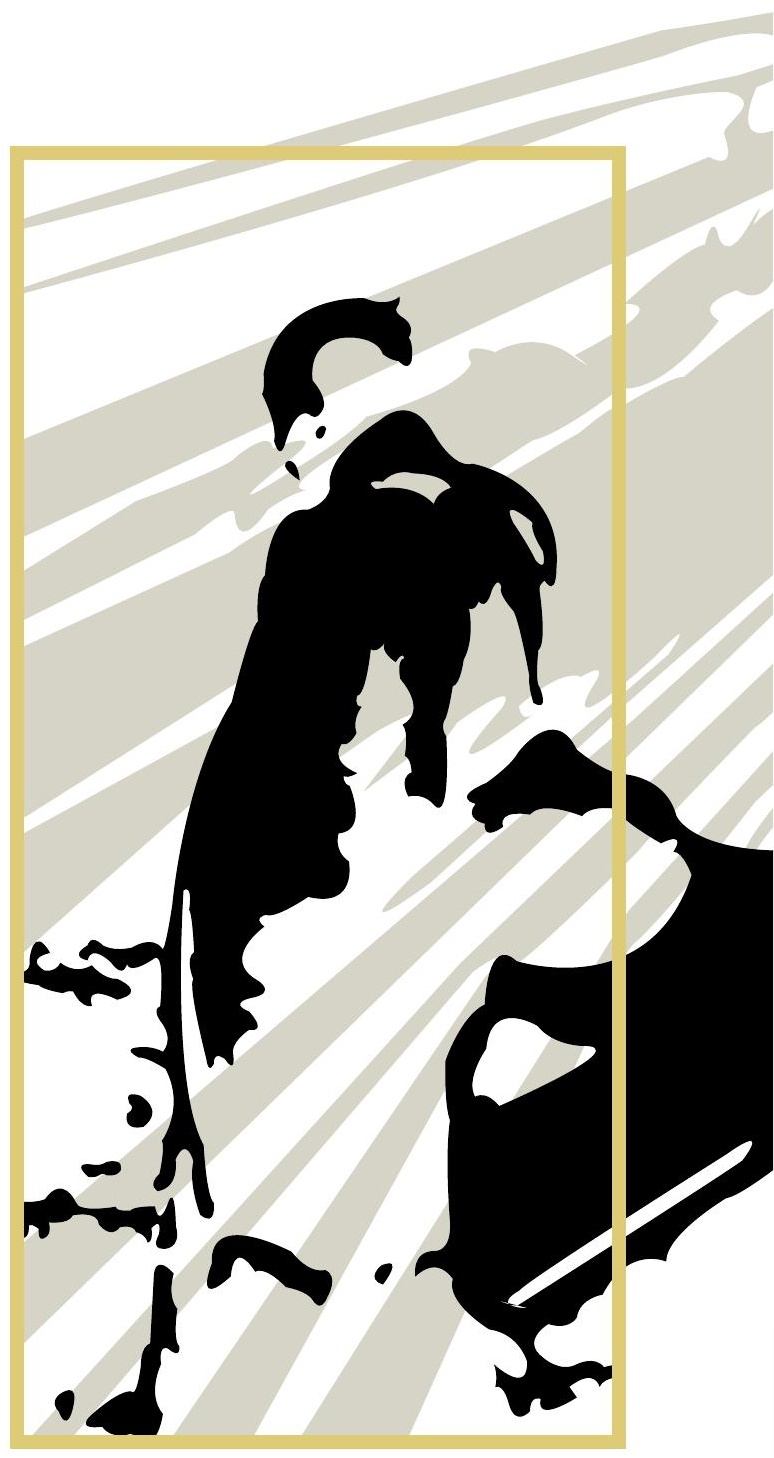

para aprofundar sua vivência da espiritualidade cristã. Temos também exemplos de pessoas que foram tocadas pelo budismo exclusivamente através da leitura de livros ou da participação em grupos de discussão pela Internet.

Recentemente um grupo de líderes de movimentos budistas tradicionais organizou o Colegiado Budista Brasileiro (CBB), entidade budista pluridisciplinar presidida por Maurício Ghigonetto, direcionada para a correta divulgação, orientação e organização dos ensinamentos do dharma no Brasil. Uma de suas atribuições é assessorar os órgãos da imprensa no sentido de evitar que transmitam informações equivocadas ou distorcidas sobre o budismo - ou os "budismos" - em nosso país, para o público. Participo do mesmo na qualidade de membro do conselho consultivo. Ricardo Sasaki e Cláudio Miklos, membros do 
CBB, mostram-se preocupados com as distorções a que o budismo se acha sujeito em nosso país e apontam também para um certo caráter "festivo" de nossa cultura, que faz muita gente se entusiasmar momentaneamente pela doutrina, porém logo se afastando, por falta de perseverança no estudo e na prática.

Quanto a mim, minha experiência de 45 anos de trabalho budista foi sempre de atuação junto a pequenos grupos, compostos de algumas dezenas de pessoas, no máximo. Acredito que obudismo brasileiro será construído através do trabalho lento, perseverante e discreto de pequenos gru- pos, quer no seio das organizações criadas pelo budismo de imigração, quer fora delas. Como historiador, quero lembrar que em países como a China e o Japão a implantação do budismo começou com pequenos grupos organizados sob a influência de missionários e residentes estrangeiros, e que o processo de consolidação do dharma nessas sociedades se estendeu por vários séculos. Conclusões a respeito de um eventual sucesso ou fracasso do budismo - ou dos "budismos" - no Brasil só poderão ser deduzidas a partir de uma história de longa duração que só poderá ser escrita num futuro ainda distante.

\section{BIBLIOGRAFIA}

ARTE TIBETANA. Catálogo da Exposição organizada pela Fundação Apis Tibetana no Museu de Arte e Arqueologia da

USP em 1968. Texto de Nana de Craiova. São Paulo, MAA-USP, 1968.

FAURE, Bernard. Bouddhismes, Philosophies et Religions. Paris, Flammarion, 1998.

GONÇALVES, Ricardo Mário. Textos Budistas e Zen-Budistas. 2a ed. revista e ampliada. São Paulo, Cultrix, 1992.

MAGALHÃES JÚNIOR, R. Poesia e Vida de Augusto dos Anjos. Rio de Janeiro, Civilização Brasileira, 1977.

NINA, Ana Cristina Lopes. Ventos da Impermanência - Um Estudo sobre a Re-significação do Budismo Tibetano no

Contexto da Diáspora. Tese de doutorado apresentada ao Programa de Pós-Graduação em Antropologia Social,

FFLCH-USP, maio de 2004.

USARSKI, Frank (org.). 0 Budismo no Brasil. São Paulo, Lorosae, 2002.

"O Dharma Verde-amarelo Mal-sucedido - um Esboço da Acanhada Situação do Budismo", in Estudos

Avançados, no 52, São Paulo, IEA-USP, set.dez./2004, pp. 303-20. 